\title{
Evoked Potential Studies in Friedreich's Ataxia and Progressive Early Onset Cerebellar Ataxia
}

\author{
M. Vanasse, L. Garcia-Larrea, Ph. Neuschwander, P. Trouillas and F. Mauguière
}

\begin{abstract}
We recorded somatosensory evoked potentials (SEP) in 15 patients affected by Friedreich's ataxia (FA) and in 9 patients with progressive early onset cerebellar ataxia (PEOCA). Brainstem auditory evoked potentials (BAEP) were also recorded in 14 FA patients and in five PEOCA patients. SEP results showed clear differences between groups of FA, evidence of peripheral involvement was seen in all patients, with absence of the N9 potential or a major reduction of its amplitude. In patients in whom central responses could be recorded, conduction velocity was normal or near normal up to the brainstem but was reduced from brainstem to cerebral cortex. Four patients with PEOCA had SEP abnormalities similar to those seen in FA. In the five other patients, the amplitude and latency of N9 were normal but conduction velocity was reduced from brainstem to cerebral cortex. In FA, BAEP were abnormal in all patients with a disease duration of four years or more but were normal in four of the five PEOCA patients. Systematic evoked potential recording is useful in the investigation of hereditary ataxias.
\end{abstract}

RÉSUMÉ: Des études de potentiels évoqués dans l'ataxie de Friedreich et dans l'ataxie cérébelleuse progressive à début précoce. Nous avons procédé à l'enregistrement de potentiels évoqués somesthésiques (PES) chez 14 patients atteints d'ataxie de Friedreich (AF) et chez neuf patients présentant une ataxie cérébelleuse évolutive à début précoce (ACEDP). De plus, nous avons étudié les potentiels évoqués auditifs précoces (PEAp) chez 14 cas d'AF et cinq d'ACEDP. Les PES ont montré des anomalies de nature différente chez ces patients. Chez tous les patients atteints d'AF, il existe une atteinte périphérique avec absence du potentiel N9 ou diminution importante de son amplitude. Chez les patients chez qui des potentiels P4 ou N20 ont pu être enregistrés, on note que la vitesse de conduction est normale ou près de la normale jusqu'au tronc cérébral mais ralentie entre le tronc et le cortex. Chez quatre patients présentant une ACEDP, les PES ont révélé des anomalies semblables à celles retrouvées dans l'AF. Chez les cinq autres cas, l'amplitude et la latence de N9 étaient normales mais la vitesse de conduction était ralentie entre le tronc cérébral et le cortex. Dans l'AF, les PEAp étaient anormaux chez tous les patients dont la maladie évoluait depuis quatre ans ou plus mais étaient normaux chez quatre des cinq patients avec ACEDP. Des enregistrements systématiques des potentiels évoqués sont utiles dans l'investigation des ataxies héréditaires.

Can. J. Neurol. Sci. 1988; 15:292-298

Inherited ataxias have received much attention over the last decade and at least three new classifications have been proposed recently. 1.2.3 These classifications have several points in common being largely based on age of onset, mode of inheritance, specific clinical features (in particular the presence or absence of deep tendon reflexes in the lower limbs) and known (such as metabolic disorders or defective DNA repair) or unknown etiology. The extensive works of Harding 1,4,5,6 and of the Québec Cooperative Study on Friedreich's Ataxia ${ }^{7}$ have led to the identification of specific clinical entities which are either variants of Friedreich's ataxia $8,9,10$ or distinct disease entities such as the autosomal recessive spastic ataxia of CharlevoixSaguenay 11 and early onset cerebellar ataxia with retained tendon reflexes. ${ }^{4}$

Several authors have studied visual evoked potentials
(VEP); $12,13,14,15,16$ brainstem auditory evoked potentials (BAEP);17,18,19,20,21,22 somatosensory evoked potentials (SEP) $23,24,25,26$ or multimodality evoked potentials $27,28,29,30,31,32$ and have described several characteristic electrophysiological abnormalities in Friedreich's ataxia (FA). Evoked potentials (EP) have also been recorded in ataxia telengiectasia, 32 olivopontocerebellar ataxias (OPCA) and various, mostly adult onset, cerebellar ataxias. 13,14,16,27,28,30

Apart from FA, progressive early onset cerebellar ataxias (PEOCA) have never been specifically studied from an EP point of view. We report here SEP recordings carried out in nine patients with PEOCA and compare the results obtained in these patients to those observed in 15 patients affected by FA. In addition five of the nine patients with PEOCA and 14 FA patients also had BAEP recordings.

From the Laboratoire de Neurophysiologie Sensorielle, Faculté de Médecine Lyon-Nord, EEG Department, Hôpital Neurologique, Lyon, France (Drs. Vanasse, Garcia-Larrea, Mauguière); Division of Neurology, Hôpital de l'Antiquaille, Lyon, France (Drs. Neuschwander and Trouillas)

Received January 19, 1988. Accepted in final form May 2, 1988

Reprint requests to: Michel Vanasse, MD, Laboratoire d'électrophysiologie médicale, Hôpital St. Justine, 3175 Côte de Ste Catherine, Montréal, Québec, Canada H3T IC9 


\begin{tabular}{|c|c|c|c|c|c|c|c|c|c|}
\hline Patient \# & 1 & 2 & 3 & 4 & 5 & 6 & 7 & 8 & 9 \\
\hline Heredity & Dominant & Dominant & Dominant & Sporadic & Sporadic & Sporadic & Sporadic & Sporadic & Recessive \\
\hline Age of onset (yrs) & 1 & 10 & 12 & 1 & 5 & 8 & 11 & 13 & 20 \\
\hline Duration (yrs) & 9 & 21 & 23 & 26 & 9 & 8 & 8.5 & 18 & 1 \\
\hline Limb ataxia & Present & Present & Present & Present & Present & Present & Present & Present & Present \\
\hline Knee jerks & Abs & Abs & Abs & Inc & Inc & Inc & Inc & lnc & Inc \\
\hline Vibration - position sense & Affected & Normal & Normal & Normal & Normal & Affected & Normal & Normal & Normal \\
\hline Fundoscopic abnormalities & None & None & None & None & None & None & None & $\begin{array}{c}\text { Optic } \\
\text { atrophy }\end{array}$ & None \\
\hline CT scan findings & $\begin{array}{c}\text { Cerebellar } \\
\text { atrophy }\end{array}$ & $\begin{array}{l}\text { Diffuse } \\
\text { atrophy }\end{array}$ & Normal & $\begin{array}{l}\text { Diffuse } \\
\text { atrophy }\end{array}$ & Normal & N.A. & N.A. & $\begin{array}{l}\text { Diffuse } \\
\text { atrophy }\end{array}$ & Normal \\
\hline \multicolumn{10}{|l|}{ Neurography } \\
\hline Motor & Normal & $\downarrow C V \downarrow A$ & Normal & Normal & Normal & Nomal & Normal & $\downarrow C V$ & Normal \\
\hline Sensory & $\downarrow C V \quad \downarrow_{A}$ & Abs & $\downarrow A$ & Normal & Normal & Normal & Normal & $\downarrow_{\mathrm{CV}} \downarrow_{\mathrm{A}}$ & Normal \\
\hline Type of EP recorded & SEP & SEP & SEP & SEP BAEP & SEP BAEP & SEP & SEP BAEP & SEP BAEP & SEP BAEP \\
\hline
\end{tabular}

$\downarrow_{A}=$ Decreased Amplitude

$\downarrow C V=$ Decreased Conduction Velocity

\section{Patients}

\section{Friedreich's ataxia (FA)}

This group includes 16 patients which satisfied all the major criteria defined by the Québec Cooperative Study on Friedreich's Ataxia. ${ }^{33}$ The mean age at the time of the recording was 28.5 years (range 14 to 53 ) and the mean duration of their disease 15.4 years (range 2 to 38 years). Fifteen had SEPs and 14 BAEPs.

\section{Progressive early onset cerebellar ataxia (PEOCA)}

All nine patients presented with a progressive cerebellar ataxia. The main clinical features are summarized in Table 1. One patient (case \#8) had ophthalmologic abnormalities consisting of a slight optic atrophy associated with increased pigmentation of the retina. In addition five patients had pes cavus (patients \#2, 5, 6, 8, 9) and three patients were mentally retarded (patients \#4, 6, 9). In patients \# 1, 2 and 3, the family history was suggestive of an autosomal dominant inheritance. In each case, one parent and other relatives in the two previous generations presented similar symptoms. Patient \#9 had a brother affected by a similar condition and this suggested an autosomal recessive inheritance, both parents being asymptomatic. The other cases were considered as sporadic. All nine had SEPs and five had BAEPs recorded.

\section{METHODS}

\section{SEP}

SEP were elicited by $0.2 \mathrm{msec}$ electrical square pulses delivered percutaneous to the median nerve at the wrist through silver disk electrodes and were recorded using either a 4- or 8channel montage of disk electrodes. In all patients this montage included electrodes located in the ipsi- and contralateral parietal regions (P'3 and P'4, $3 \mathrm{~cm}$ behind $\mathrm{C} 2$ and $7 \mathrm{~cm}$ from the midline), at supraclavicular Erb's point and at $\mathrm{Cv} 6$ spinal process. In addition, electrodes located on the contralateral frontal (F7, $\mathrm{F} 8$ ), on the mid-frontal (Fz) region and an anterior cervical (located in the neck over the cricoid bone) were also used for the 8-channel montage. A non cephalic reference situated on the shoulder on the non-stimulation side was used for all the derivations with the exception of Erb's point for which the reference
N.A. $=$ Not Available

was placed over the mid-frontal region $(\mathrm{Fz})$. Averaging was performed on 2000 responses with an analysis time of $66 \mathrm{msec}$ and a bin width of $236 \mu \mathrm{sec}$ (filter bandpass 1.6-3200 Hz, $6 \mathrm{~dB}$ down per octave). The stimuli were delivered at motor threshold for abductor pollicis brevis at a rate of $2 / \mathrm{sec}$. At least two sets of averaged responses were obtained in the same session.

\section{BAEP}

Responses to monaural stimulation were recorded with a one-channel montage between $\mathrm{Cz}$ and the mastoid on the stimulated side. The ground electrode was situated on the ear lobe contralateral to the stimulated ear. The filter bandpass of the amplifiers was set up at $160-1600 \mathrm{~Hz}(6 \mathrm{~dB}$ down). Unfiltered alternating clicks of 100 usec were delivered at a rate of $20 / \mathrm{sec}$

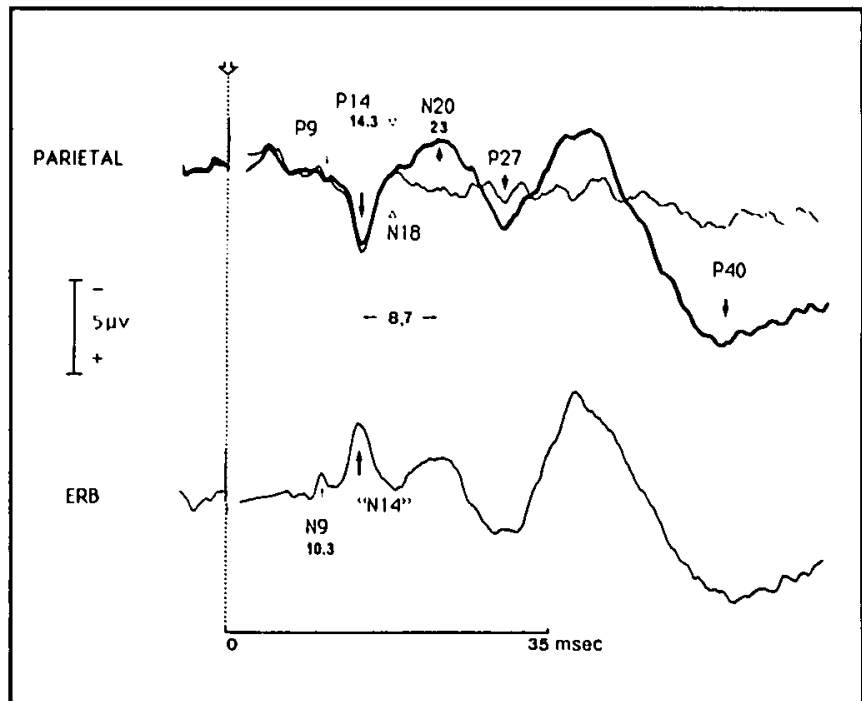

Figure I - SEP findings in a case of Friedreich Ataxia. A N9 potential of very low amplitude but normal latency is recorded at Erb's poim (cephalic reference at $F z$ ). With a parietal electrode (non-cephalic reference at the shoulder) a normal PI4 and a delayed $N 2 O$ are secn. N9-PI4 IPL (4 msec.) is within normal limits but PI4-N20 IPL (\$.7 msec.) is markedly increased, thus indicating a conduction slowing at rostrat brainstem or thalamo-cortical radiations. Notice that due to the cephalic reference in the bottom trace an inverted P/4 (labelled "N/4" in the figure) is also present which is the mirror image of the $P 14$ picked by the parietal clectrode. 
Table 2: SEP and BAEP Latencies and IPL in 16 Patients with Typical F.A.

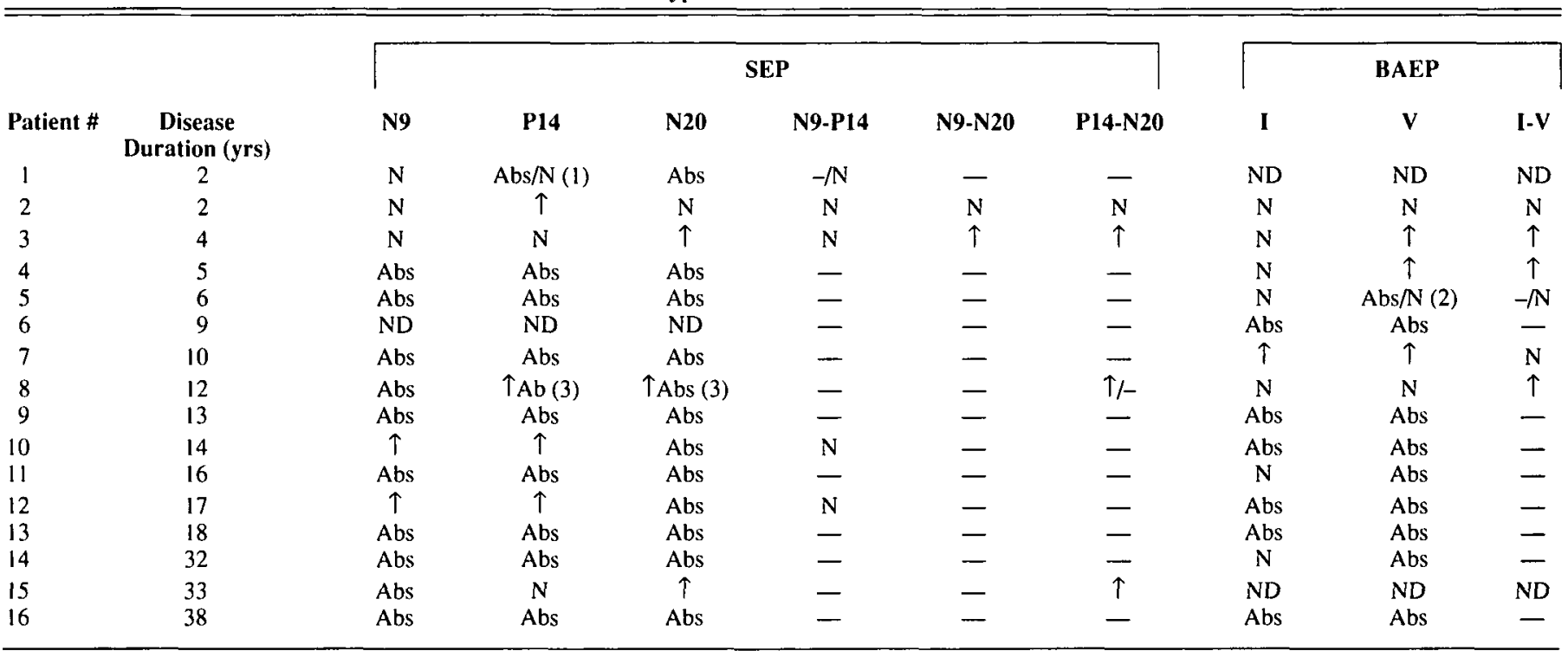

Abs = Bilateral absence of response; $\mathrm{N}=$ Bilateral normal latency or IPL; ND $=$ Not done; $\uparrow=$ Latency or IPL $\geq 2.5$ SD bilaterally as compared to normal controls. (1) In patient \#1 no P14 was obtained after right median nerve stimulation (2). In patient \#5, wave V was absent on the right side (3). In patient \#8 P14 and $\mathrm{N} 20$ were absent after left median nerve stimulation.

Table 3: SEP and BAEP Latencies and IPL in 9 Patients with PEOCA

\begin{tabular}{|c|c|c|c|c|c|c|c|c|c|}
\hline Patient \# & N9 & P14 & N20 & N9-P14 & N9-N20 & P14-N20 & I & V & I-V \\
\hline 2 & Abs & Abs & $\mathrm{Abs}$ & - & - & - & ND & ND & ND \\
\hline 3 & $\mathbf{N}$ & $\mathrm{N}$ & Abs & $\mathrm{N}$ & - & - & ND & ND & ND \\
\hline 4 & $\mathrm{~N}$ & $\mathrm{~N}$ & $\uparrow$ & $\mathrm{N}$ & $\uparrow$ & $\uparrow$ & N/Abs (1) & Abs & Abs \\
\hline 7 & $\mathrm{~N}$ & $\mathrm{~N}$ & $\mathrm{~N}$ & $N$ & $\uparrow$ & $\uparrow$ & $\mathrm{N}$ & $\mathrm{N}$ & $\mathrm{N}$ \\
\hline 8 & $\mathbf{N}$ & $\mathrm{N}$ & Abs & $\mathrm{N}$ & - & - & $\mathbf{N}$ & $\mathrm{N}$ & $\mathrm{N}$ \\
\hline 9 & $\mathrm{~N}$ & $\mathrm{~N}$ & $\mathrm{~N}$ & $\mathrm{~N}$ & $\uparrow$ & $\uparrow$ & $\mathrm{N}$ & $\mathrm{N}$ & $\mathrm{N}$ \\
\hline
\end{tabular}

Abs = Bilateral absence of response $; \mathrm{ND}=$ Not done; $\mathrm{N}=$ Bilateral normal latency or IPL; $\uparrow=$ Latency or IPL $\geq 2.5$ SD bilaterally as compared to normal controls; (1) In patient \#4, wave I was present on right side but absent on left side (2). In patient \#5, P14 and N20 were absent after right side stimulation.

successively to each ear. The non-stimulated ear was masked by white noise at $20 \mathrm{~dB}$ lower intensity than the stimulus. Each trial consisted of an average of 2560 sweeps. Time of analysis was $10 \mathrm{msec}$ with a bin width of $19.5 \mathrm{usec}$ (512 sampling points). In all patients "complete" BAEP audiometry was performed by gradually decreasing the stimulus from $100 \mathrm{dBHL}$ to wave $\mathrm{V}$ threshold. At least two trials were repeated at $100 \mathrm{~dB}$ for each patient and for each stimulated ear.

\section{RESULTS}

For SEPs we measured the amplitude and latency of N9 (brachial plexus potential obtained at Erb's point), the latencies of the scalp far-field P14 and contralateral parietal N20 potentials, as well as the N9-P14, N9-N20 and P14-N20 interpeak latencies (IPL). For BAEPs we measured the latencies of waves $I$ and $V$ and the I-V IPL. Results were considered as abnormal when exceeding the mean +2.5 S.D. of values obtained in nor- mal controls. Recording conditions were the same in controls as those described above. For BAEPs, 25 normal subjects (mean age 33.3 years, s.d. 12 years) were recorded; for SEPs, normative data were based on results obtained in 22 subjects (mean age 29 years s.d. 3.7 years).

Results are summarized in Tables 2 and 3. In FA, no patient had entirely normal SEP (Table 2 ). In eight of the 15 patients no potential could be recognized. Of the seven remaining patients, two had no N9 potential and in the five others N9 was decreased in amplitude. N9 latency was normal in three and slightly increased in two. The PI4 potential could be identified at least on one side in these seven patients including the five in whom N9 was recorded (Figure 1). P14 latency was normal in three patients and increased in four patients. N20 was obtained at least unilaterally in four patients and was normal in only one being desynchronized and of prolonged latency in the three others. The N9-P14 IPL could be measured in five patients and was normal in all of them. N9-N20 IPL was measurable in only two 


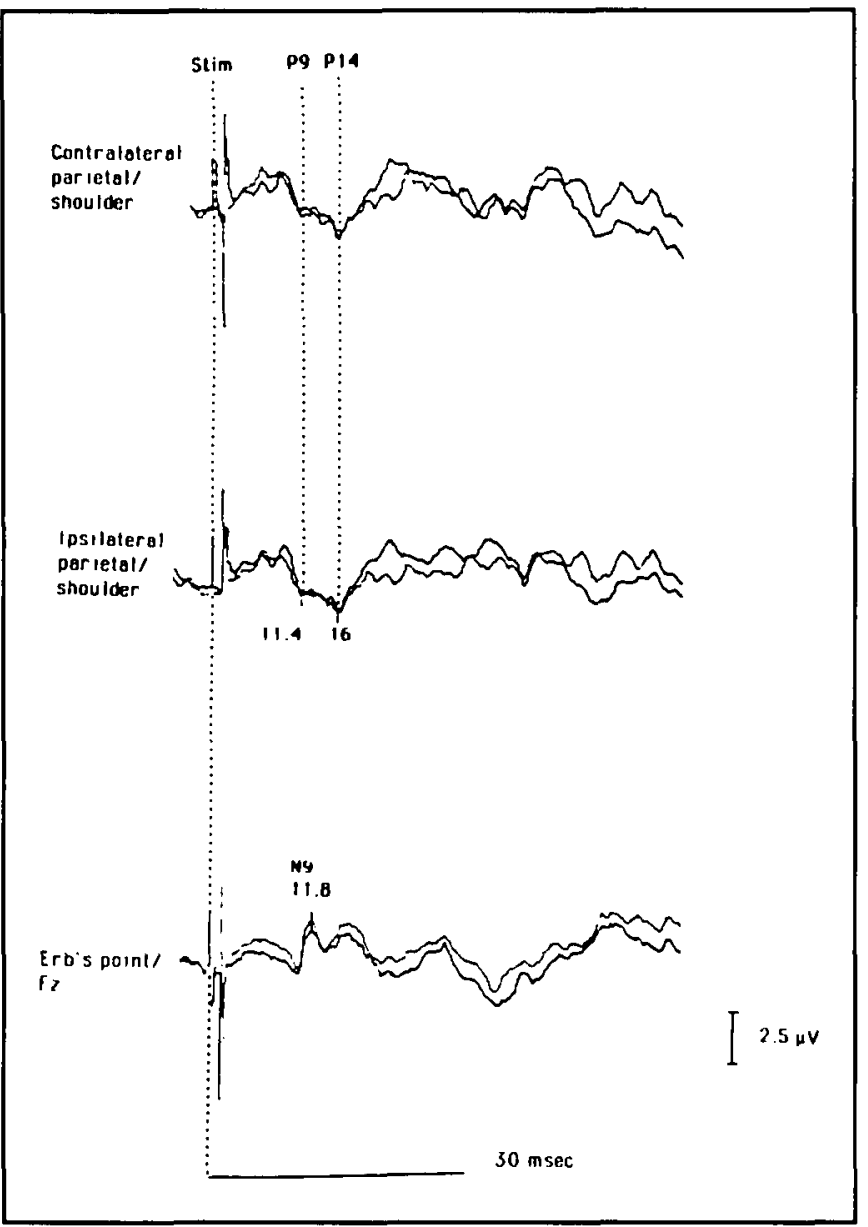

Figure 2 - SEP findings in a patient with a dominant PEOCA (case \#3). N9 is of reduced amplitude, P/4 is normal and N20 is absent. N9.P/4 IPL is within normal limits.

patients and was normal in one and increased in the other. Finally, the P14-N20 IPL was found to be prolonged in three of the four patients in whom it could be measured.

In PEOCA (Table 3), two patients (\#I and 2) had no recognizable potentials either at Erb's point or further centrally. N9 could be recorded in the seven other patients, being of normal latency in all and of reduced amplitude in two (\#3 and 8). P14 was present and of normal latency bilaterally in six patients as was the N9-P14 IPL. In patient \#5, P14 was normal with left side stimulation but absent with right median nerve stimulation. On the contrary, N20 was absent in two patients (cases \#3 and 8 , Figure 2) or delayed in three (cases $\# 4,5,6$ ) and the P14-N20 IPL was increased in the five patients in whom it could be recorded (Figure 3 ).

As can be seen in Table 2, BAEP were abnormal in 13 of 14 FA patients in whom this test was done. Clearly, the abnormalities were more important in patients with a disease of longer duration and always affected wave $V$ (Figure 4). In PEOCA (Table 3), only one of the five patients in whom it was done showed BAEP abnormalities with a disappearance of wave V.

\section{Discussion}

Our goal in carrying this study was to determine if EPs could be of some use in differentiating PEOCA cases from one anoth- er and from FA patients and try to gain information about the pathophysiology of these disorders.

As can be seen by our results, there are clear differences in SEPs between FA and PEOCA patients. Our SEP findings in FA are in agreement with what has been previously described 23,24 . $25,26,27,28,30,31,32$ and showed two types, and locations of abnormalities. In all our patients we found evidence of peripheral involvement suggested by the absence or decreased amplitude of N9, which when present appeared at a normal or near normal latency. When measurable, central conduction was abnormal in all patients except one whose illness was of short duration (\#2), indicated by $\mathrm{N} 20$ being either desynchronized (of lower amplitude and longer duration) and of prolonged latency (with increased N9-N20 and P14-N20 IPL (Figure 1) or unoblainable.

In previous studies $25.27 .31 \mathrm{~N} 13$ or $\mathrm{N} 14$ potentials recorded at the cervical level were shown to be present in most patients and of normal or near normal latency. However, these recordings were done with an $\mathrm{Fz}$ reference electrode which may create some problems in localization, since the waveform complex obtained at the cervical level with this cephalic reference is the resultant of activity from a spinal cord generator (N/3) and a brainstem generator (P14); this latter component is picked up by the reference electrode and appears as an 'N14' potential with inverse polarity (see Figure 1). ${ }^{34.35}$ Although the precise generator of Pl4 is not yet known, its brainstem origin has been demonstrated conclusively by EP studies and anatomical correlates. ${ }^{34,35,36.37}$ When present the P14 potential was of normal or

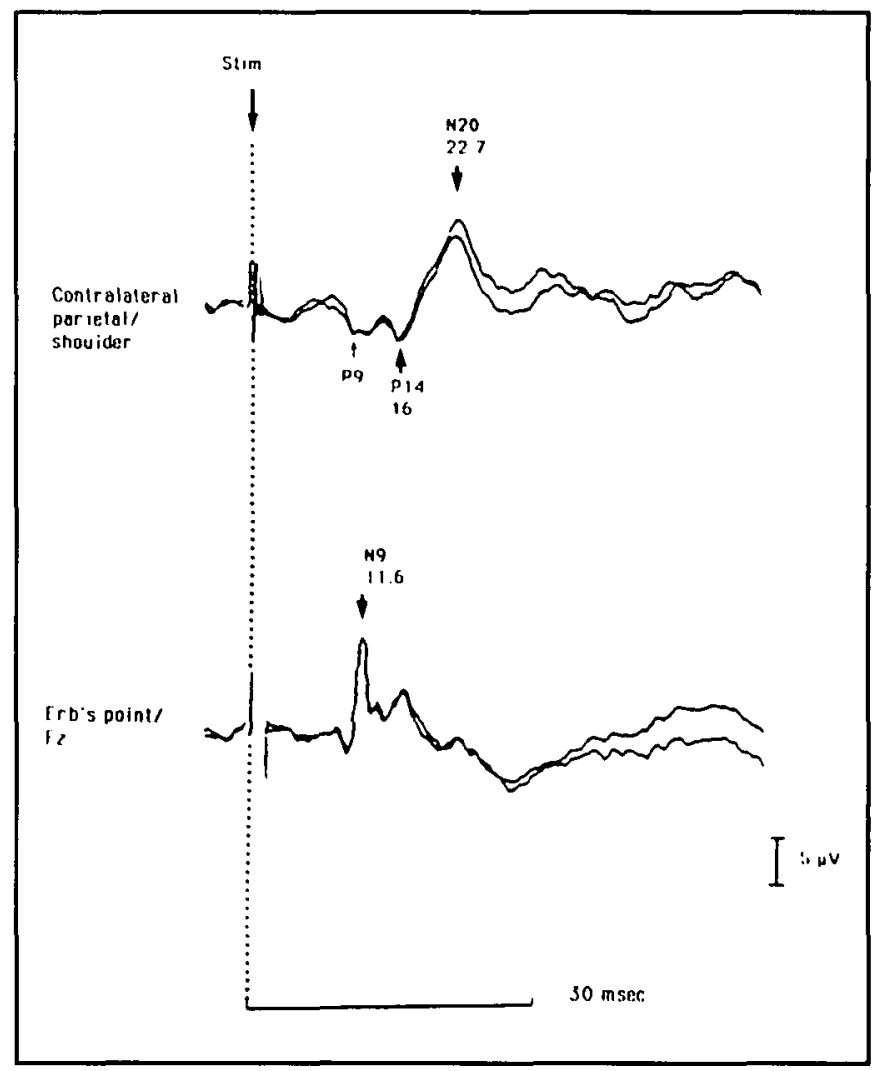

Figure 3 -SEP findings in a patient with a recessive PEOCA. Erb's point potential (N9) and brainstem P/4 are of normal latency and amplinde. Conversely. $\mathrm{N} 20$ is delayed with an abnormal PI4-N2O $I P L$. 


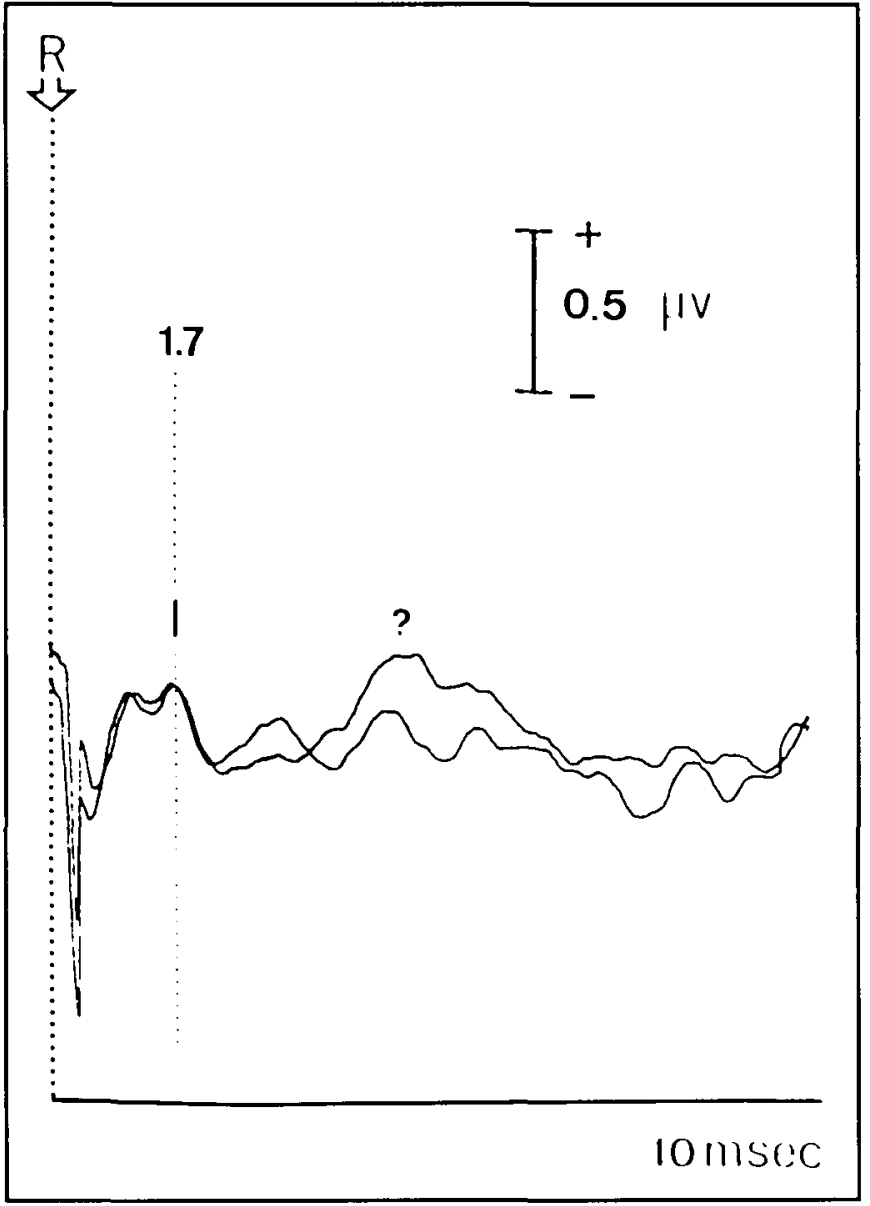

Figure 4 - BAEP findings in FA. This patient illustrates a typical $B A E P$ finding in cases of FA. Only wave $I$ is present in two consecutive trials; all subsequent components have disappeared or are markedly reduced in amplitude.

near normal latency in our FA patients and was associated with a normal N9-P14 IPL (Figure 1). This suggests that conduction velocity in somatosensory pathways serving upper limbs is unaffected up to the level of the brainstem in this disease.

In PEOCA, five of the nine patients could be distinguished from the FA group since none of them had any peripheral or brainstem involvement, N9 amplitude and latency, P14 latency and N9-P14 IPL being normal in these patients. They showed however, abnormalities indicative of central dysfunction with a prolonged N9-N20 and P14-N20 IPL seen in all patients. In the remaining four PEOCA patients the abnormalities were reminiscent of those observed in FA: in two (cases \#1 and 2) no SEP could be obtained. Both of these patients had a dominant form of ataxia and both had abnormal sensory nerve conduction velocities. In the two others, one dominant and one sporadic (cases \#3 and 8), we found a N9 potential of reduced amplitude but of normal latency; P14 latency and N9-P14 IPL were normal but N20 was absent bilaterally (Figure 2). One of them (case \#8) also had slightly decreased motor and sensory nerve conduction velocities with low amplitude sensory nerve action potentials.

BAEP abnormalities have been extensively documented in FA. 17.18,19.21,22,27.28,29,30,31,32 They were found to be abnormal in most cases with the exception of Nuwer et al 28 who reported normal results in all of the 20 FA patients they studied. BAEP are of special interest in FA since their degree of abnormality is related to the duration and severity of the disease. $18,19,21,29,31,32$ These potentials can be normal in younger patients but then become gradually abnormal, showing a rostro-caudal pattern of deterioration with wave V and I-V IPL always being affected first. Our results are again in concordance with these observations since we found abnormal BAEPs in 13 of the 14 FA patients in whom these tests were done (Figure 4). These abnormalities were of increasing severity with increasing duration of the disease. Furthermore, as can be seen in Table 2, when BAEPs were abnormal, wave $V$ was always affected (frequently absent) even though wave I was still present and of normal latency in five patients. On the contrary BAEPs were normal in four of the five PEOCA patients in whom this test was done, even though the duration of the disease was from one to 18 years in these particular patients. BAEPs were abnormal in only one patient with a PEOCA of 26 years duration.

The pathophysiology of the various EP abnormalities seen in FA is not completely understood. The decreased amplitude of N9 is probably due to a loss of nerve fibres. Degeneration of large neurons in the posterior root ganglia and the resulting disappearance of large myelinated fibres in the peripheral nerves has been well documented. ${ }^{38,39,40,41}$ Since this process is mostly one of axonal degeneration, it may explain why N9 latency is normal or near normal. However, fibre loss can not account for the increase of P14-N20 IPL. Such an increase could be more easily explained by demyelination but no significant demyelination of the thalamo-cortical projections has been found in FA patient autopsies. ${ }^{42,43.44} \mathrm{~A}$ slight to severe loss of thalamic neurons was seen in several FA patients $s^{43,44}$ affecting particularly the ventroposterolateral nucleus in one single case. ${ }^{42}$ Although these changes could explain the disappearance of N20, they could not account for the increased conduction time between the brainstem and the parietal cortex. Diffuse gliosis of the cerebral white matter and myelin pallor or a slight degeneration of the median lemniscus have been reported at autopsies of FA patients by Oppenheimer ${ }^{43}$ and Lamarche et al. ${ }^{44}$ These abnormalities could explain the increased P4-N20 interval seen in our patients since the sensory stimulations which generate SEPs are conducted by the median lemniscus to the thalamus (VPL nucleus) and the cerebral cortex.

BAEP abnormalities were first thought to be secondary to spiral ganglion degeneration since no potential could be obtained in the first patients recorded. ${ }^{17}$ This hypothesis was dismissed by several further studies showing a rostro-caudal deterioration with persisting wave $\mathbf{I}$ in many patients in whom other waves had disappeared. ${ }^{18,19,29,32}$ Jabbari et al ${ }^{19}$ suggested that there is a primary brainstem dysfunction in FA. Again, the nature of this dysfunction has not been clarified and is certainly not restricted to the brainstem since cortical auditory EP have also been found to be abnormal in FA, and these abnormalities were at least partially independent from those BAEPs in the same patients. ${ }^{18,22}$

On clinical grounds, our six sporadic or recessive PEOCA patients could be classified as early onset cerebellar ataxia with retained tendon reflexes as defined by Harding. ${ }^{4}$ From an electrophysiological point of view however, one patient (case \#8) was different from the others since he had clear evidence of 
peripheral involvement with decreased sensory and motor nerve conduction velocities and an N9 potential of low amplitude. In this same patient central involvement was also more severe than in other patients since $\mathrm{N} 20$ was absent bilaterally. This patient should thus be considered as belonging to a different category of ataxia than the other five.

The three patients with a dominant ataxia were very similar to FA patients and had definite signs of central and peripheral involvement. In two of them no peripheral or central SEP could be obtained, while in the third N9 was of decreased amplitude, P14 was normal and N20 was absent (see Figure 3). These patients are difficult to classify: a form of OPCA with peripheral neuropathy and slow ocular saccades have recently been described by Wadia ${ }^{45}$ but the very early age of onset in one patient (case \#1) and the absence of slow saccades in all three seem to differentiate our cases from theirs. Almost identical cases (except for the very early age of onset of our patient \#I) of dominant ataxia with large fibre sensory neuropathy have been recently reported by Bennett et al ${ }^{46}$ and this may represent a specific type of inherited ataxia.

The number of patients in our study is too small to enable us to make any useful contribution to the complex task of classifying inherited ataxias. We feel however that systematic electrophysiological studies of ataxic patients could be useful in such a classification in combination with clinical, biochemical and molecular genetics data. Furthermore EPs could be of value in monitoring the response to eventual drug treatment, since they may give quantifiable measurements of the disease and of its evolution. For FA, BAEPs may be of particular value since they appear to reflect the severity of the disease.

\section{ACKNOWLEDGEMENTS}

Michel Vanasse was supported by grants from Institut national de la santé et de la recherche médicale (INSERM) and Hôpital Marie-Enfant.

\section{REFERENCES}

1. Harding AE. Classification of the hereditary ataxias and paraplegias. Lancet 1983; 1: 1151-1155.

2. Barbeau A, Sadilebouiz M, Sadilebouiz A, et al. A clinical classification of hereditary ataxias. Can J Neurol Sci 1984; 11: 501505.

3. Currier R. A classification of the ataxias. Ital J Neurol Sci 1984; 4 (Suppl.): 55-64.

4. Harding AE. Early onset cerebellar ataxia with retained tendon reflexes: A clinical and genetic study of a disorder distinct from Friedreich's ataxia. J Neurol Neurosurg Psychiatry 1981; 44: 503-508.

5. Harding AE. Friedreich's ataxia: A clinical and genetic study of 90 families with an analysis of early diagnostic criteria and intrafamilial clustering of clinical features. Brain 1981; 104: 589-620.

6. Harding AE. The clinical features and classification of late onset autosomal dominant cerebellar ataxias. Brain 1982; 105: 1-28.

7. Barbeau A. The Québec Cooperative Study of Friedreich's Ataxia. Can J Neurol Sci 1984; 11: 646-660.

8. Bouchard JP, Barbeau A, Bouchard R., et al. Electromyographic and nerve conduction studies in Friedreich's ataxia and autosomal recessive spastic ataxia of Charlevoix-Saguenay. Can J Neurol Sci 1979a; 6: 191-194.

9. Bouchard JP, Barbeau A, Bouchard R., et al. A cluster of Friedreich's ataxia in Rimouski, Quebec. Can J Neurol Sci 1979b; 6: 205-208.
10. Barbeau A, Roy M, Sadilebouiz M, et al. Recessive ataxia in Acadians and "Cajuns". Can J Neurol Sci 1984; 11: 526-533.

11. Bouchard JP, Barbeau A, Bouchard R, et al. Autosomal recessive ataxia of Charlevoix-Saguenay. Can J Neurol Sci 1978; 5: 6169.

12. Carroll WH, Kriss A, Baraister $M$, et al. The incidence and nature of visual involvement in Friedreich's ataxia. A clinical and visual evoked potential study. Brain 1980, 103: 413-434.

13. Bird TD, Crill WE. Pattern reversal visual evoked potentials in the hereditary ataxias and spinal degeneration. Ann Neurol 1981; 3 : 243-250.

14. Livingstone IR, Mastaglia FL, Edis R, et al. Visual involvement in Friedreich's ataxia and hereditary spastic ataxia. Arch Neurol 1981; 38: 75-79.

15. Wenzel W, Camcho L, Claus S, et al. Visually evoked potentials in Friedreich's ataxia. In: Duvoisin RC, Plaitakis A, eds. The Olivopontocerebellar Atrophies (Advances in Neurology). Raven Press, New York, 1984: 21.

16. Ghezzi A, Montani R. Comparative study of visual evoked responses in cerebellar ataxias and multiple sclerosis. Acta Neurol Scand 1985; 71: 252-256.

17. Satya-Murti S, Cacace A, Hanson P. Auditory dysfunction in Friedreich's ataxia: Result of spiral ganglion degeneration. Neurology 1980: 1047-1053.

18. Taylor MJ, McMenamim JB, Andermann E, el al. Electrophysiologic investigation of the auditory system in Friedreich's ataxia. Can J Neurol Sci 1982; 9: 131-135.

19. Jabbari B, Schwartz D, McNeil DM, et al. Early abnormalities of brainstem auditory evoked potential in Friedreich's ataxia Evidence of primary brainstem dysfunction. Neurology 1983; 33: 1071-1073.

20. Ell J, Prasher D, Rudge P. Neuro-otological abnormalities in Friedreich's ataxia. J Neurol Neurosurg Psychiatry 1984; 47: 2632.

21 Filla A, De Michele G, Brescia-Morra V, et al. Clinical and biochemical studies in Freidreich's ataxia. Ital J Neurol Sci 1984, 4 (Suppl.): 47-54.

22. Rossi L, Amantini A, deScisciolo G, et al. Auditory evoked potentials in Friedreich's ataxia and olivopontocerebellar atrophy. Ital J Neurol Sci 1984, 4 (Suppl.): 182-191.

23. Desmedt JE, Noel P. Averaged cerebral evoked potentials in the evaluation of lesions of the sensory nerves and of the central somatosensory pathways. I $n$ : Desmedt JE, ed. New Developments in Electromyography and Clinical Neurophysiology, Karger, Basel 1973; 2: 352-371.

24. Sauer M, Schenck E. Electrophysiological investigation in Friedreich's herdoataxia and in hereditary motor and sensory neuropathy. Electroencephalog Clin Neurophysiol 1977; 43: 623.

25. Jones SJ, Baraister M, Halliday AM. Peripheral and central somatosensory nerve conduction defects in Friedreich's ataxia. J Neurol Neurosurg Psychiat 1980; 43: 495-503.

26. Noel P, Desmedt JE. The somatosensory pathway in Friedreich 's ataxia. Acta Neurol Belg 1976; 76: 271 .

27. Pedersen L, Trojaborg W. Visual auditory and somatosensory pathway involvement in hereditary cerebellar ataxia, Friedreich's ataxia and familial spastic paraplegia. Electroencephalogr Clin Neurophysiol 1981; 52: 283-297.

28. Nuwer MR, Perlman S, Packwood JW, et al. Evoked potential abnormalities in the various inherited ataxias. Ann Neurol 1983; 13: $20-27$

29. Bogacz J, Chouza C, Romero S, et al. Visual evoked potentials and brainstem auditory evoked potentials in Friedreich's ataxia - A longitudinal study. Can J Neurol Sci 1984; 11: 565-569.

30. Cosi L, Piccolo G, Callieco R. Evoked potentials studies in Friedreich's ataxia and olivopontocerebellar atrophy. Ital J Neurol Sci 1984; 4 (Suppl.): 172-181. 
31. Pelosi L, Fels A, Petrillo A, et al. Friedreich's ataxia: Clinical involvement and evoked potentials. Acta Neurol Scand 1984; 70: 360-368.

32. Taylor MJ, Chan Lui WY, Logan NJ. Longitudinal evoked potential studies in hereditary ataxias. Can J Neurol Sci 1985; 12: 100-105.

33. Geoffroy G, Barbeau A, Breton G, et al. Clinical description and roentgenologic evaluation of patients with Freidreich's ataxia. Can J Neurol Sci 1976; 3: 279-286.

34. Mauguiere F, Desmedt JE, Courjon J. Neural generators of N18 and Pl4 far-field somatosensory evoked potentials in patients with lesions of thalamus or thalamo-cortical radiations. Electroencephalogr Clin Neurophysiol 1983; 56: 283-292.

35. Mauguiere F, Ibanez V. The dissociation of early SEP components in lesions of the cervico-medullary junction. Electroencephalogr Clin Neurophysiol 1985; 62: 406-420.

36. Anziska BJ, Cracco RQ. Short latency SEPs to median nerve stimulation: Comparison of recording method and origin of components. Electroencephalogr Clin Neurophysiol 1981; 52: 531-539.

37. Desmedt JE. Neural generators of somatosensory evoked potentials components in man. In: Struppler A, Weindl A, eds. Electromyography and Evoked Potentials, Springer-Verlag, Berlin 1985: 160-168.

38. Hugues JT, Brownell B, Hewer RL. The peripheral sensory pathway in Friedreich's ataxia: An examination by light and electron microscopy of the posterior nerve roots, posterior root ganglia and peripheral sensory nerves in cases of Friedreich's ataxia. Brain 1968; 91: 803-820.

39. McLeod JG. An electrophysiological and pathological study of peripheral nerves in Friedreich's ataxia. J Neurol Sci 1971; 12: 333-349.

40. Lamarche J, Luneau C. Lemieux B. Ultrastructural observations on spinal ganglion biopsy in Freidreich's ataxia: A preliminary report. Can J Neurol Sci 1982; 9: 137-139.

41. Thomas PK. Peripheral nerve pathology and physiopathology in the inherited ataxias. Ital J Neurol Sci 1984; 4 (Suppl.): 90-97.

42. Boudin G. Grossiord A, Guillard A, et al. Maladie de Friedreich avec atteintes systématiques sus médullaires. Rev Neurol 1972; 127: $441-456$

43. Oppenheimer DR. Brain lesions in Friedreich's ataxia. Can J Neurol Sci 1979; 6: 173-176.

44. Lamarche J, Lemieux B, Lieu HB. The neuropathology of "typical" Friedreich's ataxia. Can J Neurol Sci 1984; 11: 592-600.

45. Wadia NH. A variety of olivopontocerebellar atrophy distinguished by slow eye movements and peripheral neuropathy. $I n$ : Duvoisin RC, Plaitakis A, eds. The Olivopontocerebellar Atrophies (Advances in Neurology), Raven Press, New York 1984: 21.

46. Bennett RH, Ludvigson $P$, de Leon $G$, et al. Large fibres sensory neuropathy in autosomal dominant spinocerebellar degeneration. Arch Neurol 1984; 41: 175-178. 